Part of Journal of Research of the National Bureau of Standards, Volume 34, February 1945

\title{
SPECTROGRAPHIC DETERMINATION OF SODIUM, POTAS- SIUM, AND LITHIUM IN PORTLAND CEMENT WITH THE DIRECT-CURRENT CARBON ARC
}

\author{
By Armin W. Helz*
}

\section{ABSTRACT}

Spectrographic methods, which are much less time-consuming than the usual chemical methods, are described for the determination of sodium, potassium, and lithium in portland cement. For the determination of sodium and potassium the sample is mixed with a mineral base containing silver for the internal standard. For lithium a standard mixture of graphite and strontium carbonate is added to the cement sample. In either case a fixed amount of the resultant mixture is placed in the crater of a graphite electrode, which is made the lower positive element of a direct-current arc. The Na $8194.81 \mathrm{~A}, K 7698.98 \mathrm{~A}$, and $\mathrm{Li} 3232.61 \mathrm{~A}$ lines are used for the quantitative calculations. A discussion of the development. of the method is given, followed by details of the adopted analytical procedure. The spectrographic analyses of 41 cements for sodium and potassium are given for comparison with the chemical values.

\section{CONTENTS}

I. Introduction

II. Method of analysis for sodium and potassium 130

1. Choice of method ...... 130

2. Choice of spectral region

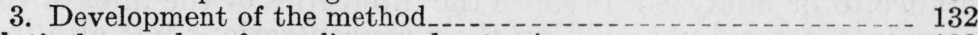

III. Analytical procedure for sodium and potassium

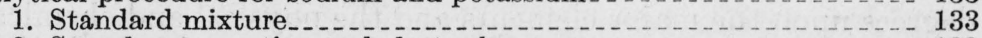

2. Sample preparation and electrodes _...

3. Making the spectrogram

4. Photometry and analytical curves...................... 134

5. Procedure for high $\mathrm{K}_{2} \mathrm{O}$ content $\ldots$

6. Time required...

IV. Results of analysis for sodium and potassium

V. Determination of lithium

VI. Summary _ .

VII. References . .

\section{INTRODUCTION}

Spectrographic analysis depends upon the fact that elements of a substance can be made to radiate light, a spectrum of which has many lines characteristic of the elements in the source. The relative intensities of these lines for different elements bear a definite relation to the relative quantities, kind, and number of elements in the source, but

\footnotetext{
* Research Associate at the National Bureau of Standards, representing the Portland Cement Association.
} 
with the present state of knowledge of spectroscopy, this relation is too complicated to predict. It has been found that by controlling the excitation used for the source and dividing analytical problems into type cases, empirical data may be obtained that will give a rapid analytical method. This method of analysis is ideally suited to problems in which (1) a rapid determination is required, (2) the size of the sample is necessarily small, (3) the concentrations of the elements in question are small, or (4) the chemical method is difficult or uncertain. Many examples may be found in the literature on the subject where the accuracy of the results is as good as that of the best chemical methods, and the time for the analysis is a matter of minutes for the spectrographic method as compared to hours for the chemical method.

The percentage error of spectrographic analysis tends to remain constant regardless of the concentration, whereas, in chemical analysis, the absolute error tends to be constant. Thus, for high concentration, chemical methods are preferable to spectrographic methods, whereas for low concentrations the reverse is true. In general, spectrographic analysis has proved advantageous for the determination of concentrations of elements below about 5 percent.

The interest in spectrographic methods by the cement industry arises from the presence in portland cement of small quantities of metallic elements, the specific effects of which it is important to study. Of particular significance at this time are the alkali elements, which are under critical observation by various laboratories in connection with questions on the durability of concrete [1]. ${ }^{1}$ In the present paper, the elements considered are potassium, sodium, and lithium. The spectrographic method does not require the difficult separations that are involved in the chemical determinations of the alkali elements, and it is much less time-consuming. This advantage of speed will be even greater if the method is extended to include other minor elements, such as magnesium, manganese, and titanium.

No general method of spectrographic analysis has proved entirely satisfactory. It is necessary to make a study of the type of substance to be analyzed, because the intensities of the lines of the minor elements depend not only on their concentrations but also in various degrees upon the major elements and the physical and chemical states of all the elements present. Portland cement, with its limited variability of the major components, may be treated as a single type of material for spectrographic analysis. Primary considerations for this application are the preparation of the sample and excitation of the spectrum. Subsequent details of spectroscopy and photography are readily decided according to established principles. The spectrographic procedure is outlined in detail for the benefit of those in the ceramic industry who are not familiar with this field.

\section{METHOD OF ANALYSIS FOR SODIUM AND POTASSIUM}

\section{CHOICE OF METHOD}

In this study, the widely used internal-standard principle of Gerlach and the rotating-stepped-sector method of plate calibration were adopted. For discussions of these matters, papers by Duffendack,

\footnotetext{
1 Figures in brackets indicate the literature references at the end of the paper.
} 
Wolfe, and Smith [2], Twyman [3], Pierce and Nachtrieb [4], Scribner [5], and Owens [6] may be consulted. But the problems involved in the treatment of the sample, the excitation of the spectrum, and the choice of the spectral region best suited to the present conditions could be settled only by a planned program of experimental tests.

Characteristics of portland cement, of immediate significance in its spectrographic analysis, are its low electrical conductivity, and its ability to sinter and melt at the temperature of the electric arc. Procedures suitable for use with this type of material may be found in the literature relative to the analysis of minerals and inorganic chemicals [6 to 15], ceramic materials [16, 17], and ignited biological materials $[6,7,9,18,19,24]$. A common treatment is to place a small quantity of the sample in the crater of a graphite electrode $[7,16,20]$. The sample is often mixed with graphite $[11,14,17,23]$ or a base material free from the elements sought [13, 19] and bearing with it an internal standard ${ }^{2}[2,4]$ and a spectroscopic buffer ${ }^{2}$ [24].

The sample mixture may be compressed into pellets and placed on a graphite electrode [7] or used as the electrode alone [21,22]. A method designed to use a solution may also be considered because the alkalies in portland cement are readily brought into solution by treatment with dilute hydrochloric acid. The solution may be injected into a flame [9] or a small amount dried on a graphite electrode $[8,10,12,20]$ for arc or spark excitation.

The kind of excitation to use for best results is interrelated to a considerable extent with the condition of the sample. In the references given for the sample treatments discussed in the preceding paragraph, four kinds of excitation are noted: (1) flame, (2) direct-current arc, (3) alternating-current arc (stabilized by the use of a high-voltage, current-limited circuit), and (4) condensed spark.

Several methods and a great many variations in procedure for the determination of the alkalies in portland cement were explored, but for one reason or another were rejected in favor of the direct-current arc procedure. An alternating-current arc [8] with the sample mixed with a powdered metal or graphite and compressed into pellets [21,22] indicated good possibilities except for requirements of rigidly controlled operating conditions. A solution of the cement sample dried on a graphite electrode for use in an alternating-current arc $[8,12]$ proved to be impractical because of low intensity of the alkali lines. In the method finally adopted, a fixed quantity of the sample was placed in a cupped graphite electrode and used in a direct-current arc. The preliminary survey indicated good possibilities and at the same time the simplest solution of the problem.

\section{CHOICE OF SPECTRAL REGION}

It was desired to determine the alkali elements in concentrations between about 0.05 percent and 1.5 percent, the latter value being

\footnotetext{
${ }^{2}$ Because of unequal vaporization and excitation conditions from sample to sample and variations in photographic properties from plate to plate, the intensity of a spectral line of the "unknown" element is measured relative to that of a line of an element either in the sample in a constant concentration or added to the sample. This is the "internal standard," which should possess the following properties: (1) The reference line should be in the same wavelength region as the analysis line, (2) the excitation characteristics of both lines should be similar, (3) the two elements should have similar vaporization rates, (4) the intensities of the two lines should be similar, and (5) a uniform dispersion of the reference material throughout the sample should be obtained. For practical considerations the internal standard may not have all of the above properties, and variations in the results may be noted from sample to sample due to the presence of extraneous elements and variations in the excitation. These differences may be diminished by the addition of a "spectroscopic buffer"-an element (usually having a relatively high vapor pressure and a low ionization potential) which tends to maintain uniform excitation in the arc.
} 
about the upper limit of concentration of any one alkali element in commercial cements. With the direct-current carbon arc the following lines have intensities convenient for quantitative work (expressed in wavelength in angstroms): ${ }^{3} \mathrm{Na}, 3302.32,8194.81$ and $K, 4044.14$, 7698.98. Lines in the 3,200 to 4,500 region have the advantage over lines in the 7,300 to 8,600 region in that they may be photographed on plates much more suitable for quantitative work. The $K 4044.14$ line, however, occurs in a region of strong cyanogen bands, which interfere with measurements of intensity; but this background may be effectively reduced by a special exposure procedure or by the use of a nitrogen-free atmosphere $[18,19]$ for the arc. The 7,300 to 8,600 region has much less background interference, but here a difficulty is encountered with the $K 7698.98$ line, which exhibits self-reversal for the higher potassium concentrations. ${ }^{4}$ (See fig. 1, B.) However, certain refinements and improvements in the procedure made it possible to use that line. Therefore the red region was chosen for the analytical procedure. This is illustrated in figure 1. Spectra D1 and $D 2$ are in the $8,500 \mathrm{~A}$ to $7,600 \mathrm{~A}$ region. Each spectrum is divided into five strips of known relative intensity for photometric purposes, explained later in the text.

\section{DEVELOPMENT OF THE METHOD}

The self-reversal of the potassium lines noted in the powder method was observed only for cements having the higher potassium concentrations and was found to be subject to a partial control by an adjustment of the flow of air around the arc and of the concentration of the sample. Powdered graphite and alumina made the condition more acute, but silica improved the spectrum, forming, however, a refractory melt that gave the arc erratic burning characteristics. A mixture of silica, alumina, and calcium carbonate, which when mixed with the cement sample produces in the arc a fluid low-temperature melt, effectively reduced the self-reversal of the potassium lines. Under these conditions the potassium in the sample evaporated at a steady rate for a period of about 1 minute. The addition of lithium carbonate to the mixture, for buffer action, further improved the behavior of the melt, but erratic results were still obtained, owing to the large volume of gas liberated in the arc. This sudden release of carbon dioxide in some instances forced drops of the sample mixture to flow over the rim of the crater, but it was found that this could be prevented by prefusion of the mixture or the use of a largerdiameter electrode having a conical-drilled crater. Furthermore, the use of this new electrode also decreased the rate of evaporation of the alkali elements by requiring a longer time to reach the maximum temperature.

Silver, introduced as the oxide, was selected for the internal standard because of the similarity in rate of evaporation of silver and the alkalies and the favorable supply of reference lines for sodium and potassium. This internal standard is not ideal but is a practical compromise. For this reason, particular precision was required with such details in the procedure as the weight of the sample in the electrode, the time of exposure, the arc current, the arc gap and its position in relation to the spectrograph.

3 An angstrom is equal to $10^{-8} \mathrm{~cm}$.

4 "Self-reversal" is a decrease in the intensity of a spectral line caused by the absorption of radiation from atoms in the central part of the source by atoms of the same kind in the outer part of the source. Such lines appear very broad, blurred, and often completely transparent in the center. 


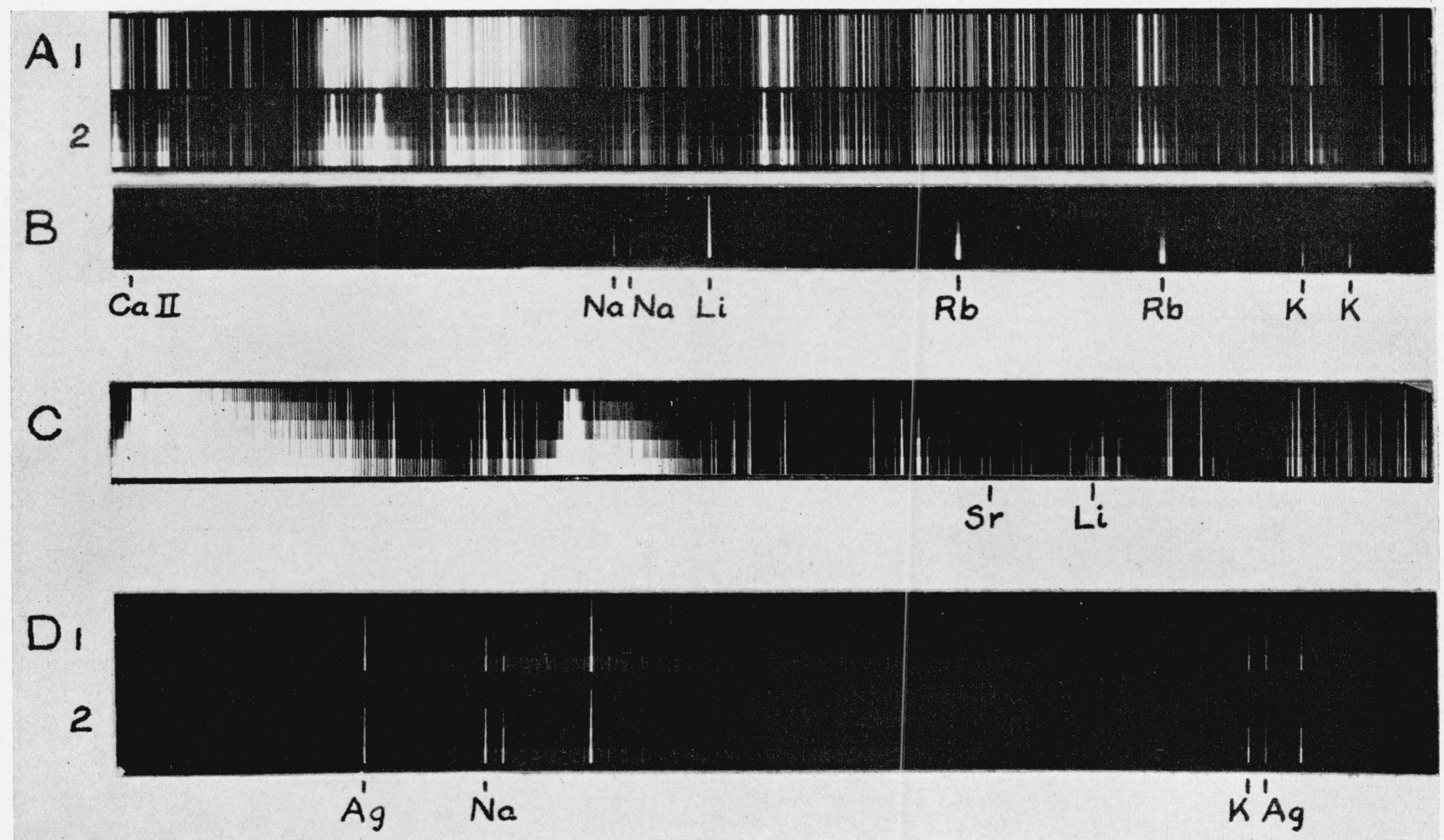

Figure 1.-Illustrations of the intensity pattern, self-reversal, and typical spectra for the determination of the alkalies. $A$, spectrum in the 4,000 to $3,000 \mathrm{~A}$ region. 1, uniform illumination, 2, pattern produced by the rotating-stepped sector. $B$, spectrum in the 8,500 to $7,600 \mathrm{~A}$ region showing the alkali lines. The Rb lines are self-reversed.

$C$, spectrum for the lithium determination of a cement sample containing 0.15 of percent $\mathrm{Li}_{2} \mathrm{O}$. The lithium and strontium (internal standard) lines used for the

$D$, spectrum for the sodium and potassium determinations showing the sodium, potassium, and silver (internal standard) lines used in the determination. Sample 1 contains 0.08 percent of $\mathrm{Na}_{2} \mathrm{O}$ and 0.35 percent of $\mathrm{K}_{2} \mathrm{O}$. Sample 2 contains 0.74 percent of $\mathrm{Na}_{2} \mathrm{O}$ and 0.69 percent of $\mathrm{K}_{2} \mathrm{O}$.

Spectra $A$ and $B$ were made with a spectrograph having slightly less dispersion than that for spectra $C$ and $D$. All spectra in the plate are shown with decreasing wavelength to the right. 


\section{ANALYTICAL PROCEDURE FOR SODIUM AND POTASSIUM}

\section{STANDARD MIXTURE}

The standard mixture used in the preparation of the sample for analysis of potassium and sodium is made by thoroughly mixing 60 percent (by weight) of $\mathrm{SiO}_{2}, 14$ percent of $\mathrm{Al}_{2} \mathrm{O}_{3}, 20$ percent of $\mathrm{CaCO}_{3}$, and 6 percent of $\mathrm{Li}_{2} \mathrm{CO}_{3}$. Highest purity powdered chemicals are used. The mixture is fused in a platinum boat by heating in an electric furnace to $1,300^{\circ} \mathrm{C}$, cooled and crushed to pass a No. 100 sieve. An amount of finely divided silver oxide (alkali free) is added equal in weight to one-tenth of the weight of the fused and ground product just described. Thorough mixing by alternately grinding in an agate mortar and sifting through a No. 100 sieve completes the preparation of the standard mixture. Thirty grams of this mixture is a sufficient quantity for use in analyzing 100 cement samples.

\section{SAMPLE PREPARATION AND ELECTRODES}

For the determination of sodium and potassium, $0.300 \mathrm{~g}$ of the $\mathrm{CaO}-\mathrm{Al}_{2} \mathrm{O}_{3}-\mathrm{SiO}_{2}-\mathrm{Li}_{2} \mathrm{O}$ mixture is mixed with $0.100 \mathrm{~g}$ of the portland cement sample. Small glass vials are convenient for weighing, mixing, and storing the samples. Time is saved if a number of vials are filled in advance with the required amount of the standard mixture. After the addition of the cement sample, mixing is accomplished with the use of an agate mortar and pestle and by sifting through a small No. 100 sieve. Thirty milligrams of the mixture is placed in each of two graphite electrodes prepared for duplicate results.

The electrodes are cut from second grade, spectroscopic carbons, which are suitable for the determination of the alkalies in concentrations above 0.1 percent. The upper electrode consists of a 1-inch length of $1 / 8$-inch-diameter stock with a tapered "pencil" point. The lower electrode similar to the design of Scribner and Corliss [25] consists of two parts, (1) a base and pedestal cut from $1 / 4^{-}$or $1 / 8$-inch-diameter stock, which is clamped to the arc stand and acts as a support for (2) the cap which carries the sample. With this design the samplebearing area of the electrode obtains a more uniform and higher temperature than with the usual one-piece design. The base may be used several times, but the cap and cathode are good for only a single exposure. The cap consists of a 15 -mm length of $3 / 8$-inch-diameterstock graphite with a hole in each end, one to fit the pedestal, which may be cylindrical, but preferably the shape of a truncated cone, and the other to receive the sample. The sample hole has conical sides starting at the top with a diameter of $8 \mathrm{~mm}$ and tapering down to $4-\mathrm{mm}$ diameter at a depth of $4 \mathrm{~mm}$. For a depth of $3 \mathrm{~mm}$ beyond this point, the hole continues with a cylindrical shape $4 \mathrm{~mm}$ in diameter. Special lathe tools make the cutting of these caps a simple and rapid operation.

\section{MAKING THE SPECTROGRAM}

A grating spectrograph having a dispersion of about 5 A per millimeter was used. This high dispersion is incidental, however, and not necessary for this procedure. Uniformity of illumination at the slit is aided by placing at the slit a convex lens [5], which produces an image of the arc on the grating of the spectrograph. Because the arc 
in this work is an extended source with a large flame, and also because the vertical distribution of intensity of the internal standard lines is different from that of the alkali lines, additional specification of the illumination is necessary. Good illumination is obtained with the arc in such a position that the upper limit of its inverted image, or the rim of the lower electrode, coincides with the upper edge of the grating. The image of the upper electrode then falls well within the grating area. This setting and the readjustment required during the burning of the arc to keep the gap at a specified value may be facilitated by projecting an image of the arc on a screen on the side of the arc opposite the spectrograph. A rotating stepped sector $[4,5]$ for producing a relative-intensity pattern, and a filter, complete the optics outside the spectrograph. Light from the arc passes in order: filter, sector, lens, and slit. A Corning, Noviol B, G38 filter is needed for the sodium-potassium determination if a grating spectrograph is used. This filter cuts out the light of wavelength shorter than $4500 \mathrm{~A}$.

The electrode holder, or arc stand $[20,25]$, should be designed to provide rapid vertical adjustment of both electrodes, adjustment of the upper electrode during the exposure to keep the gap constant, and controlled ventilation.

A 220-volt direct-current power supply with the current controlled at 10 amperes is used. The lower sample-bearing electrode is made positive [20] and the gap set at $4 \mathrm{~mm}$. An exposure time of 90 seconds is used, starting with the striking of the arc. The arc is conveniently started by the use of an auxiliary circuit, which momentarily induces a high-frequency, high-voltage, low-current spark across the gap [26]. However, the results are the same as when the simpler starting method is used of shorting with a carbon rod. Eastman IIR spectrographic plates are used. The plates in this study were processed in automatically rocked, temperature-controlled trays.

\section{PHOTOMETRY AND ANALYTICAL CURVES}

The determination of the relative intensities of the spectral lines and their correlation with the concentration of the elements follow standard procedures, for which many references may be found $[4,5]$. Measurements of the blackening of the lines are made with a nonrecording microphotometer. The lines measured are $\mathrm{K} 7698.98 \mathrm{~A}, \mathrm{Ag}$ 7687.78 A, Na 8194. $81 \mathrm{~A}$, and $\mathrm{Ag} \mathrm{8273.52} \mathrm{A.} \mathrm{A} \mathrm{graph} \mathrm{of} \mathrm{blackening}$ versus logarithm of the relative intensity is made for each region of the spectrum and for each plate. The most suitable steps of the alkali and internal-standard lines are measured and calculated to relative intensity with the use of the plate-calibration curve.

The alkali concentration is determined by reference to an analytical curve giving the relation between concentration and relative intensity. This is determined by carrying out the entire spectrographic procedure on cements of known alkali content.

\section{PROCEDURE FOR HIGH $\mathrm{K}_{8} \mathrm{O}$ CONTENT}

It has been stated that the direction of the arc flame, towards or away from the spectrograph, affects the self-reversal of the potassium lines. This has been reduced by the choice of a standard mixture; 
but was not completely eliminated for high $\mathrm{K}_{2} \mathrm{O}$ concentrations. This difficulty may be surmounted in either of two ways.

(1) The ventilation of the arc chamber may be controlled to keep the arc flame on the side of the upper electrode nearest the spectrograph. The draft required is very gentle and should not be strong enough to make the arc burn erratically. If the arc chamber is properly ventilated, the self-reversal is not significant for $\mathrm{K}_{2} \mathrm{O}$ concentrations below 1.0 percent. If no draft is used, the limit of applicability of the procedure outlined in the preceding sections is lowered to about 0.6 or 0.7 percent of $\mathrm{K}_{2} \mathrm{O}$.

(2) The procedure to be used here and also for $\mathrm{K}_{2} \mathrm{O}$ concentrations above 1.0 percent where controlled ventilation is used is followed exactly as outlined to the point of measuring the intensity of the lines. A visual inspection is made to exclude from measurement those potassium lines obviously self-reversed. An analysis of the rejected samples for potassium is repeated with a more dilute mixture. Instead of taking $0.3 \mathrm{~g}$ of the standard mixture and $0.1 \mathrm{~g}$ of the cement sample (3 to 1), $0.450 \mathrm{~g}$ of the standard mixture and $0.050 \mathrm{~g}$ of the cement sample are taken (9 to 1). All other details of the procedure are the same, except of course the requirement of another analytical curve made with the more dilute mixture.

\section{TIME REQUIRED}

The procedure is rapid, requiring about 4 hours for the determination of sodium and potassium in six samples as compared with 30 hours for the chemical procedure. Increasing the number of samples and the extension of the spectrographic method to include other minor elements would increase the time advantage of the spectrographic method over chemical methods. The 4 hours for the spectrographic method does not include the time required to cut graphite electrodes and to prepare the standard mixture. These may be prepared in large quantities and kept on hand.

\section{RESULTS OF ANALYSIS FOR SODIUM AND POTASSIUM}

The analytical, or working curve, when plotted in terms of the logarithm of the relative intensity (alkali line relative to the internalstandard line) and the logarithm of the concentration of the alkali, should be a straight line [4]. This was the case for $\mathrm{K}_{2} \mathrm{O}$, but the $\mathrm{Na}_{2} \mathrm{O}$ curve deviated from linearity owing to some sodium contamination either in the electrodes or in the standard mixture. In all the calculations the concentrations of the oxides of the alkali elements are used rather than those of the elements, to conform with the customary procedure for reporting analysis of cements. ${ }^{5}$

The reproducibility of the method is shown in table 1. Results are given for 18 individual determinations of $\mathrm{Na}_{2} \mathrm{O}$ and $\mathrm{K}_{2} \mathrm{O}$ in the same sample. The deviations of values from the average illustrates the errors due to fluctuations in the arc, inhomogeneity of the sample,

\footnotetext{
3 The samples for determining the analytical curves for $\mathrm{Na}_{2} \mathrm{O}$ and $\mathrm{K}_{2} \mathrm{O}$ were analyzed by J. J. Tregoning of the Clay and Silicate Products Division of this Bureau.
} 
and inconsistencies in photometric measurements. The probable errors shown in the table (4.0 percent for duplicate determinations of $\mathrm{Na}_{2} \mathrm{O}$ and 5.8 percent for $\mathrm{K}_{2} \mathrm{O}$ ) represent the precision of the method, but the accuracy is demonstrated best by a comparison of the analyses of a large number of portland cements as is done in table 2 , in which the average of the spectrographic results on each cement is compared with chemical results. ${ }^{6}$ The average percentage difference between the chemical and spectrographic results is 0.06 for $\mathrm{Na}_{2} \mathrm{O}$ and 0.07 for $\mathrm{K}_{2} \mathrm{O}$. This shows a much greater percentage error relative to the average concentration of $\mathrm{Na}_{2} \mathrm{O}$ and $\mathrm{K}_{2} \mathrm{O}$ than is indicated by the probable errors reported in table 1. This larger error cannot be ascribed alone to inaccuracies in the spectrographic method as it also includes inaccuracies in the chemical method.

TABLE 1.-Reproducibility of the method for $\mathrm{Na}_{2} \mathrm{O}$ and $\mathrm{K}_{2} \mathrm{O}$ as indicated by 18 determinations on the same sample of cement

[Sample No. 1]

\begin{tabular}{|c|c|}
\hline $\mathrm{Na}_{2} \mathrm{O}$ * & $\mathrm{K}_{2} \mathrm{Ob}$ \\
\hline $\begin{array}{rr}\% & \\
& 0.33 \\
& .37 \\
& .41 \\
& .38\end{array}$ & $\begin{array}{c}\% \\
0.34 \\
.25 \\
.33 \\
.27\end{array}$ \\
\hline $\begin{array}{l}.37 \\
.34 \\
.34 \\
.34\end{array}$ & $\begin{array}{l}.31 \\
.26 \\
.32 \\
.24\end{array}$ \\
\hline $\begin{array}{l}.34 \\
.33 \\
.35 \\
.35\end{array}$ & $\begin{array}{r}.27 \\
.32 \\
.33 \\
.37\end{array}$ \\
\hline $\begin{array}{l}.36 \\
.34 \\
.40 \\
.35\end{array}$ & $\begin{array}{r}.33 \\
.27 \\
.28 \\
.33\end{array}$ \\
\hline $\begin{array}{l}.38 \\
.44\end{array}$ & $\begin{array}{l}.30 \\
: 33\end{array}$ \\
\hline Average_.. 0.36 & 0.30 \\
\hline
\end{tabular}

- Probable error for $\mathrm{Na}_{2} \mathrm{O}: 1$ determination, $5.7 \%$ of the concentration; 2 determinations, 4.0. - Probable error for $\mathrm{K}_{2} \mathrm{O}$ : 1 determination, 8.2; 2 determinations, 5.8.

Tables 3 and 4 give more detailed data for the first 21 cements listed in table 2. Two spectrographic "results" are given, a "result" being the average of two determinations. The chemical values are the average of two or more determinations (with the exclusion of widely divergent values) and were obtained by five different laboratories. The roman numerals at the head of columns of chemical results designate the laboratories, and the letters $A$ and $B$ designate the method ( $A$, modified Berk-Roller [27] and $B$, the ASTM [28] method). The average difference between the maximum and minimum chemical results of different laboratories is 0.06 percent, which is the same as the difference between chemical and spectrographic results.

Obtained through the courtesy of the Portland Cement Association; Berk-Roller method used. 
Also the average difference between the chemical results I $A$ and I $B$ is greater than the average difference between single determinations for either I $A$ or I $B$ (not shown in the table). 'These observations emphasize that reproducibility alone is not a measure of the

TABLE 2.-Comparison of the results for $\mathrm{Na}_{2} \mathrm{O}$ and $\mathrm{K}_{2} \mathrm{O}$ (in percent) obtained by the spectrographic and the chemical (Berk-Roller) methods

\begin{tabular}{|c|c|c|c|c|c|c|}
\hline \multirow{2}{*}{ Cement number } & \multicolumn{3}{|c|}{$\mathrm{Na}_{2} \mathrm{O}$} & \multicolumn{3}{|c|}{$\mathrm{K}_{2} \mathrm{O}$} \\
\hline & $\begin{array}{l}\text { Spectro- } \\
\text { graphic }\end{array}$ & Chemical & Difference & $\begin{array}{l}\text { Spectro- } \\
\text { graphic }\end{array}$ & Chemical & Difference \\
\hline 5 & $\begin{array}{r}0.21 \\
.38 \\
.04 \\
.14\end{array}$ & $\begin{array}{r}0.24 \\
.36 \\
.03 \\
.06\end{array}$ & $\begin{array}{r}-0.03 \\
+.02 \\
+.01 \\
+.08\end{array}$ & $\begin{array}{r}0.43 \\
.40 \\
.24 \\
1.55\end{array}$ & $\begin{array}{r}0.59 \\
.45 \\
.19 \\
1.37\end{array}$ & $\begin{array}{l}-0.16 \\
-.05 \\
+.05 \\
+.18\end{array}$ \\
\hline $\begin{array}{l}6 \\
6 \\
7 \\
8 \\
9-1 \\
9\end{array}$ & $\begin{array}{l}.06 \\
.34 \\
.10 \\
.10\end{array}$ & $\begin{array}{l}.06 \\
.28 \\
.07 \\
.16\end{array}$ & $\begin{array}{l}0 \\
+.06 \\
+.03 \\
-.06\end{array}$ & $\begin{array}{r}0.24 \\
.42 \\
.47 \\
.18\end{array}$ & $\begin{array}{r}0.19 \\
.49 \\
.44 \\
.13\end{array}$ & $\begin{array}{l}+.05 \\
+.07 \\
+.03 \\
+.05\end{array}$ \\
\hline $\begin{array}{l}10 \\
11- \\
12\end{array}$ & $\begin{array}{l}.30 \\
.31 \\
.58 \\
.15\end{array}$ & $\begin{array}{l}.25 \\
.26 \\
.66 \\
.05\end{array}$ & $\begin{array}{l}+.05 \\
+.05 \\
-.08 \\
+.10\end{array}$ & $\begin{array}{r}.46 \\
.36 \\
.20 \\
1.48\end{array}$ & $\begin{array}{r}.44 \\
.39 \\
.15 \\
1.36\end{array}$ & $\begin{array}{l}+.02 \\
-.03 \\
+.05 \\
+.12\end{array}$ \\
\hline $\begin{array}{l}14 \\
15 \\
16\end{array}$ & $\begin{array}{l}.28 \\
.26 \\
.28 \\
.34\end{array}$ & $\begin{array}{l}.25 \\
.28 \\
.27 \\
.32\end{array}$ & $\begin{array}{l}+.03 \\
-.02 \\
+.01 \\
+.02\end{array}$ & $\begin{array}{r}0.58 \\
.27 \\
.38 \\
.32\end{array}$ & $\begin{array}{r}0.54 \\
.26 \\
.46 \\
.26\end{array}$ & $\begin{array}{l}+.04 \\
+.01 \\
-.08 \\
+.06\end{array}$ \\
\hline $\begin{array}{l}18 \\
19 \\
20 \\
21- \\
21-\ldots-\ldots . . .\end{array}$ & $\begin{array}{l}.08 \\
.15 \\
.30 \\
.96\end{array}$ & $\begin{array}{r}.05 \\
.16 \\
.38 \\
1.17\end{array}$ & $\begin{array}{l}+.03 \\
-.01 \\
-.08 \\
-.21\end{array}$ & $\begin{array}{r}1.35 \\
0.34 \\
.06 \\
.16\end{array}$ & $\begin{array}{r}1.28 \\
0.24 \\
.04 \\
.12\end{array}$ & $\begin{array}{r}+.07 \\
+.10 \\
+.02 \\
+.04\end{array}$ \\
\hline 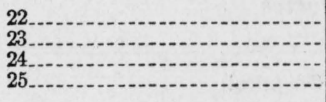 & $\begin{array}{l}.09 \\
.56 \\
.20 \\
.30\end{array}$ & $\begin{array}{r}0.08 \\
.42 \\
.17 \\
.24\end{array}$ & $\begin{array}{l}+.01 \\
+.14 \\
+.03 \\
+.06\end{array}$ & $\begin{array}{l}.30 \\
.86 \\
.16 \\
.82\end{array}$ & $\begin{array}{r}.27 \\
.74 \\
.18 \\
1.03\end{array}$ & $\begin{array}{l}+.03 \\
+.12 \\
-.02 \\
-.21\end{array}$ \\
\hline $\begin{array}{l}26 \\
27 \\
28 \\
29\end{array}$ & $\begin{array}{l}.33 \\
.40 \\
.25 \\
.39\end{array}$ & $\begin{array}{l}.31 \\
.29 \\
.22 \\
.28\end{array}$ & $\begin{array}{l}+.02 \\
+.11 \\
+.03 \\
+.11\end{array}$ & $\begin{array}{l}.40 \\
.48 \\
.20 \\
.47\end{array}$ & $\begin{array}{r}0.51 \\
.48 \\
.22 \\
.49\end{array}$ & $\begin{array}{l}-.11 \\
0 \\
-.02 \\
-.02\end{array}$ \\
\hline $\begin{array}{l}30 \\
31 \\
32 \\
33\end{array}$ & $\begin{array}{l}.18 \\
.38 \\
.14 \\
.15\end{array}$ & $\begin{array}{r}.23 \\
.39 \\
.16 \\
.08\end{array}$ & $\begin{array}{l}-.05 \\
-.01 \\
-.02 \\
+.07\end{array}$ & $\begin{array}{l}.52 \\
.53 \\
.16 \\
.67\end{array}$ & $\begin{array}{l}.41 \\
.57 \\
.16 \\
.68\end{array}$ & $\begin{array}{l}+.11 \\
\stackrel{0}{0.04} \\
-.01\end{array}$ \\
\hline $\begin{array}{l}34 \\
35 \\
36 \\
37\end{array}$ & $\begin{array}{r}.33 \\
.12 \\
.14 \\
1.06\end{array}$ & $\begin{array}{l}.31 \\
.09 \\
.12 \\
.74\end{array}$ & $\begin{array}{l}+.02 \\
+.03 \\
+.02 \\
+.32\end{array}$ & $\begin{array}{l}.54 \\
.56 \\
.20 \\
.52\end{array}$ & $\begin{array}{l}.52 \\
.44 \\
.19 \\
.69\end{array}$ & $\begin{array}{l}+.02 \\
+.12 \\
+.01 \\
-.17\end{array}$ \\
\hline $\begin{array}{l}38 \\
39 \\
40 \\
41\end{array}$ & $\begin{array}{r}0.11 \\
.40 \\
.18 \\
.13\end{array}$ & $\begin{array}{l}.06 \\
.43 \\
.08 \\
.21\end{array}$ & $\begin{array}{l}+.05 \\
-.03 \\
+.10 \\
-.08\end{array}$ & $\begin{array}{l}.17 \\
.36 \\
.47 \\
.14\end{array}$ & $\begin{array}{l}.26 \\
.33 \\
.35 \\
.14\end{array}$ & $\begin{array}{l}-.09 \\
+.03 \\
+.12 \\
0\end{array}$ \\
\hline $42 \ldots$ & .17 & .10 & +.07 & .34 & .28 & +.06 \\
\hline A verage (disregarding sign) & . & $\cdots$ & 0.058 & $\cdots$ & $\cdots$ & 0.066 \\
\hline
\end{tabular}

accuracy of either the spectrographic or the chemical method. The best estimate of the suitability of the spectrographic method for any particular application is to be gained from a study of the data in table 2 comparing the spectrographic results with chemical results for a large number and large variety of cements. 
TABLE 3.-Comparison of results for $\mathrm{Na}_{2} \mathrm{O}$ (percent) obtained by the spectrographic method and by different chemical laboratories

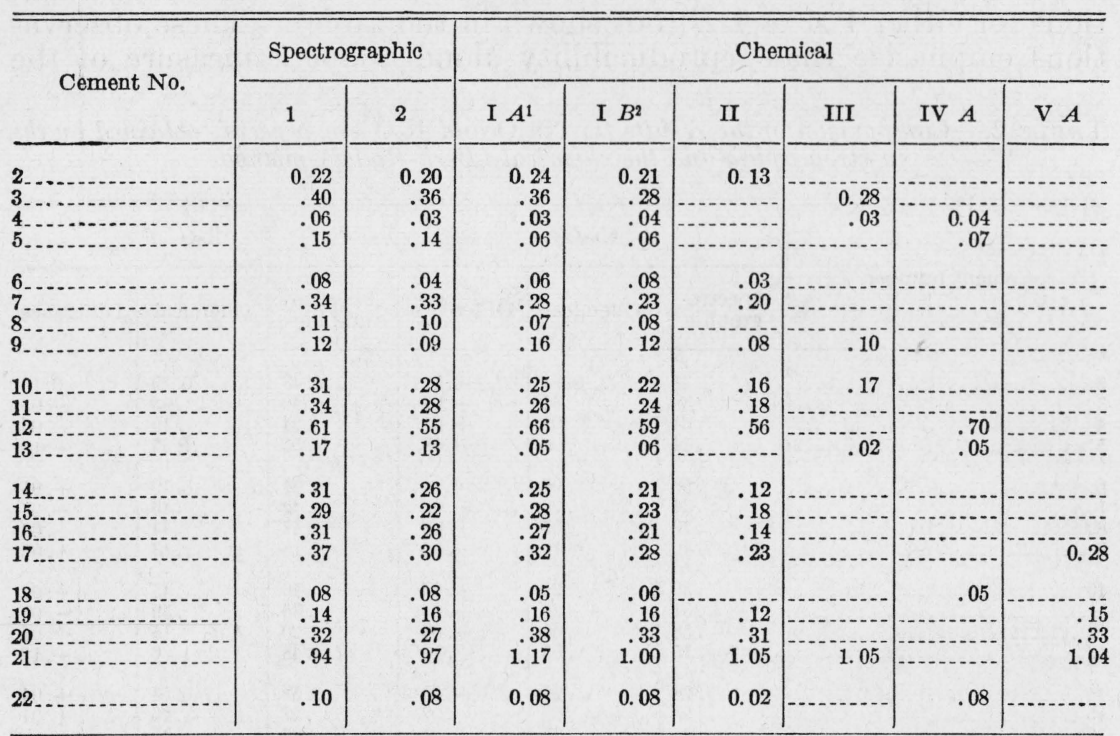

i $A$, Modified Berk-Roller method [27].

$B$, ASTM method [28].

TABLE 4.-Comparison of results for $\mathrm{K}_{2} \mathrm{O}$ (percent) obtained by the spectrographic method and by different chemical laboratories

\begin{tabular}{|c|c|c|c|c|c|c|c|c|}
\hline \multirow{2}{*}{ Cement No. } & \multicolumn{2}{|c|}{ Spectrographic } & \multirow{2}{*}{ I $A^{1}$} & \multicolumn{5}{|c|}{ Chemical } \\
\hline & 1 & 2 & & I $B^{2}$ & II & III & IV A & V A \\
\hline $\begin{array}{l}2 \ldots \\
3 \ldots \\
4 \\
5 \\
\ldots\end{array}$ & $\begin{array}{r}0.41 \\
.43 \\
.25 \\
31.50\end{array}$ & $\begin{array}{r}0.45 \\
.37 \\
.24 \\
81.60\end{array}$ & $\begin{array}{r}0.59 \\
.45 \\
.19 \\
1.37\end{array}$ & $\begin{array}{r}0.51 \\
.40 \\
.19 \\
1.30\end{array}$ & $\begin{array}{r}0.56 \\
.46 \\
.21 \\
1.37\end{array}$ & $\begin{array}{r}0.39 \\
.14\end{array}$ & $\begin{array}{l}0.21 \\
1.40\end{array}$ & 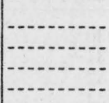 \\
\hline $\begin{array}{l}6 \ldots \\
7 \ldots \ldots \\
8 \\
9 . \ldots\end{array}$ & $\begin{array}{r}0.23 \\
.41 \\
.47 \\
.19\end{array}$ & $\begin{array}{r}0.26 \\
.44 \\
.47 \\
.16\end{array}$ & $\begin{array}{r}0.19 \\
.49 \\
.44 \\
.13\end{array}$ & $\begin{array}{r}0.23 \\
.46 \\
.43 \\
.13\end{array}$ & $\begin{array}{l}0.21 \\
.44 \\
.40 \\
.11\end{array}$ & 0.08 & -- & \begin{tabular}{l}
$-\cdot-$ \\
\hdashline- \\
\hdashline- \\
--
\end{tabular} \\
\hline 10 & $\begin{array}{r}.44 \\
.37 \\
.20 \\
31.45\end{array}$ & $\begin{array}{r}.48 \\
.36 \\
.20 \\
81.50\end{array}$ & $\begin{array}{r}.44 \\
.39 \\
.15 \\
1.36\end{array}$ & $\begin{array}{r}.40 \\
.37 \\
.14 \\
1.30\end{array}$ & $\begin{array}{r}.45 \\
.39 \\
.10 \\
1.38\end{array}$ & $\begin{array}{c}.38 \\
1.31\end{array}$ & $\begin{array}{l}0.15 \\
1.40\end{array}$ & $-\cdots$ \\
\hline 16 & $\begin{array}{r}0.47 \\
.29 \\
.40 \\
.33\end{array}$ & $\begin{array}{r}0.69 \\
.25 \\
.35 \\
.31\end{array}$ & $\begin{array}{l}0.54 \\
.26 \\
.46 \\
.26\end{array}$ & $\begin{array}{r}0.54 \\
.23 \\
.44 \\
.28\end{array}$ & $\begin{array}{r}0.57 \\
.30 \\
.48 \\
.25\end{array}$ & . & & 0.28 \\
\hline 19 & $\begin{array}{r}31.45 \\
0.33 \\
.05 \\
.16\end{array}$ & $\begin{array}{r}1.25 \\
0.35 \\
.06 \\
.15\end{array}$ & $\begin{array}{r}1.28 \\
0.24 \\
.04 \\
.12\end{array}$ & $\begin{array}{r}1.19 \\
0.26 \\
.01 \\
.08\end{array}$ & $\begin{array}{c}1.22 \\
0.29 \\
.08\end{array}$ & 0.05 & 1.30 & $\begin{array}{l}.28 \\
.01 \\
.08\end{array}$ \\
\hline 22 & .27 & .34 & .27 & .22 & .32 & & 0.27 & \\
\hline
\end{tabular}

1 , Modified BerkRoller methód [27].

$2 B$,ASTM method [28].

The potassium line with the usual (3 to 1) mixture for these cements showed self-reversal. These values were determined with a 9 to 1 mixture. See page 134 . 


\section{DETERMINATION OF LITHIUM}

An extension of the spectrographic method to include all the alkali elements, that is, lithium, cesium, and rubidium was considered. The determination of these elements by chemical methods is so difficult that the development of a spectrographic method would be useful in spite of the possibility of these elements occurring in cement only rarely. It appeared possible that lithium might be found in appreciable amounts in portland cement, and therefore a spectrographic procedure for its determination was developed. The method was designed to determine $\mathrm{Li}_{2} \mathrm{O}$ in amounts above 0.05 percent.

In the selection of the lithium line to be employed for the determination, it was noted that $\mathrm{Li} 3232.61 \mathrm{~A}$ had some advantages over other possible lines in being of the desired intensity and located in a spectral region that would permit the simultaneous determination of lithium with a number of the other minor elements in cement. These advantages seemed to outweigh the objection that, in its use, the simultaneous determination of lithium with sodium and potassium would not be possible. The $\mathrm{Li} 3232.61 \mathrm{~A}$ line was therefore selected for this study.

Synthesized standards containing lithium were prepared in two ways. (1) Lithium carbonate was added to a $\mathrm{CaO}-\mathrm{Al}_{2} \mathrm{O}_{3}-\mathrm{SiO}_{2}$ mixture to give a product containing 2.89 percent of $\mathrm{Li}_{2} \mathrm{O}$. (2) Lithium carbonate was added to a low-total-alkali cement to give a product containing 2.00 percent of $\mathrm{Li}_{2} \mathrm{O}$. These mixtures were calcined at $1,300^{\circ} \mathrm{C}$, then cooled and ground and a chemical analysis made to check the lithium content. The above mixtures were then diluted with additional amounts of the base material to give a series of samples containing $\mathrm{Li}_{2} \mathrm{O}$ between 0.10 and 1.0 percent.

The procedure used for the determination was similar to the one for sodium and potassium. A standard mixture consisting of 70 percent of graphite and 30 percent of $\mathrm{SrCO}_{3}$ (internal standard) was used. The graphite may be obtained from the powdered product of cutting and shaping electrodes. It is sieved to eliminate the size fraction above No. 100 sieve. Two-tenths gram of the graphite $\mathrm{SrCO}_{3}$ mixture is used with $0.2 \mathrm{~g}$ of the cement sample. Thirty milligrams of the resultant mixture is placed in a graphite electrode for the arc. A 40-second exposure on an Eastman spectrum analysis No. I plate is used with an arc current of $10 \mathrm{amp}$ and arc gap of $4 \mathrm{~mm}$. A ground-glass screen in the optical path near the arc was used to diminish the intensity of the spectrum in preference to the use of a much shorter exposure time. The Li $3232.61 \mathrm{~A}$ and $\mathrm{Sr} 3301.74 \mathrm{~A}$ (or $\mathrm{Sr} 3322.23 \mathrm{~A}$ ) lines are measured for the analytical calculations.

No lithium was detected in 30 portland cements analyzed, indicating that $\mathrm{Li}_{2} \mathrm{O}$ was not present in concentrations exceeding the limit of sensitivity for which the procedure was designed, about 0.05 percent. To detect lower concentrations was considered of no interest at this time.

There remains the possibility that lithium is present in some form less easily detectable than that in the synthetic samples used for the analytical curve, although the procedure employed (heating of the samples after the addition of lithium carbonate) diminishes the probability of such an error. The reliability of the method was 
checked by the use of materials of known lithium content, (1) a clay containing 0.21 percent of $\mathrm{Li}_{2} \mathrm{O}$ and (2) a spodumene containing 6.35 percent of $\mathrm{Li}_{2} \mathrm{O}$. The clay as obtained was analyzed spectrographically whereas the spodumene was added to several portland cements of widely varying $\mathrm{K}_{2} \mathrm{O}$ and $\mathrm{Na}_{2} \mathrm{O}$ contents in such amount as to produce mixtures containing 0.15 percent of $\mathrm{Li}_{2} \mathrm{O}$. The alkali contents and spectrographic results for $\mathrm{Li}_{2} \mathrm{O}$ are given in table 5 .

TABLE 5.-Comparison of results for $\mathrm{Li}_{2} \mathrm{O}$ (in percent)

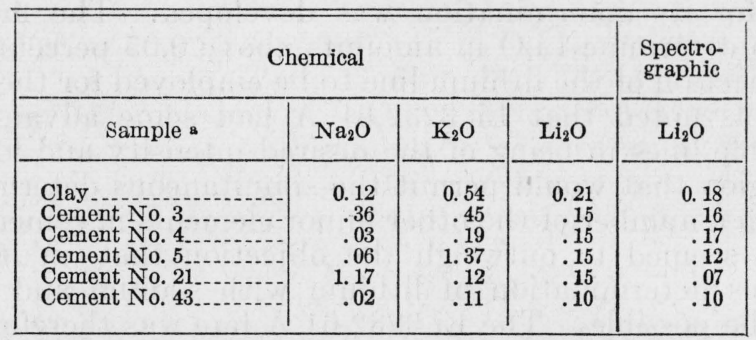

- The chemical values for lithium were obtained as follows: Clay, chemical analyses; cements 3, 4, 5, and 21 , the addition of spodumine; 43 , the addition of lithium carbonate.

It will be noted that in general the agreement between the spectrographic and chemical values for $\mathrm{Li}_{2} \mathrm{O}$ is good, the chief exceptions being noted with cements 5 and 21 . This illustrates a condition, sometimes experienced, of the effect of one element on the spectral intensity of another element. In cements 5 and 21 , where the $\mathrm{K}_{2} \mathrm{O}$ content in the first case and the $\mathrm{Na}_{2} \mathrm{O}$ content in the second case are high, the $\mathrm{Li}_{2} \mathrm{O}$ result is too low. The chief reason for this was found to be an enhancement of the intensity of the strontium line (internal standard) by the extraneous alkali element, with only a minor effect on the intensity of the lithium line. Problems of this character could be solved satisfactorily by further experimentation on technique and buffer agents, but the absence of quantities of $\mathrm{Li}_{2} \mathrm{O}$ as high as 0.05 percent in the cements examined made further perfection of the procedure seem unwarranted.

\section{SUMMARY}

Procedures are described for the spectrographic determination of sodium, potassium, and lithium in portland cement by means of the direct-current carbon arc. Sodium and potassium are determined simultaneously by mixing the sample with a mineral base, by the use of a fixed amount of the mixture in an arc and recording the red region of the spectrum. For lithium, a mixture of the sample with a graphite base is used and the violet region of the spectrum recorded. Internal standards (silver and strontium) and spectrographic buffers are introduced with the standard mixtures. The $\mathrm{Na} 8194.81 \mathrm{~A}, \mathrm{~K} 7698.98 \mathrm{~A}$, and $\mathrm{Li} 3232.61 \mathrm{~A}$ lines are used for the analytical calculations. The procedures are rapid, requiring about 4 hours for the determination of sodium and potassium in six samples and about the same time for lithium.

The procedure was designed to minimize and control self-reversal, unequal rate of evaporation of the alkali and reference elements, 
unequal distribution in the arc of intensity of the spectrum of the alkali and reference elements, and the effect of extraneous elements.

An estimate of the reproducibility of the sodium and potassium determinations in terms of the probable error for the average of duplicate determinations is 4.0 percent of the $\mathrm{Na}_{2} \mathrm{O}$ concentration and 5.8 percent of the $\mathrm{K}_{2} \mathrm{O}$ concentration. The accuracy of the method cannot be expressed in such simple figures but is illustrated by a comparison of chemical and spectrographic analyses of 41 portland cements where the spectrographic results were found to differ from the chemical results by an average value of 0.06 percent (of the sample). Chemical results obtained in five different laboratories are given in this comparison.

The spectrographic examinations of 30 portland cements for lithium indicated that in no case was $\mathrm{Li}_{2} \mathrm{O}$ present in amounts in excess of 0.05 percent. The method was checked by the analysis of several cements to which spodumene of known $\mathrm{Li}_{2} \mathrm{O}$ content had been added.

The writer is indebted to the Optics Division of this Bureau for the facilities of the spectroscopic laboratory in which the experimental work of this research was performed, and especially to B. F. Scribner for the results of his preliminary study of this problem and for his continued interest and advice throughout the study reported in this paper.

\section{REFERENCES}

[1] Report of Committee C-1 on Cement, Notes on the effect of alkalies in portland cement on the durability of concrete, Proc. Am. Soc. Testing Materials 43, 199 (1943).

[2] O. S. Duffendack, R. A. Wolfe, and R. W. Smith, Quantitative analysis by spectrographic methods, Ind. Eng. Chem. Anal. Ed. 5, 226 (1933).

[3] F. Twyman, The Spectrochemical Analysis of Metals and Alloys, p. 95 (Chemical Publishing Co., Inc., New York, N. Y., 1941).

[4] W. C. Pierce and N. H. Nachtrieb, Photometry in spectrochemical analysis, Ind. Eng. Chem. Anal. Ed. 13, 774 (1941).

[5] B. F. Scribner, Spark spectrographic analysis of commercial tin, NBS J. Research 28, 165 (1942) RP1451.

[6] J. S. Owens, Spectrochemical methods for trace analysis, Ind. Eng. Chem. Anal. Ed. 11, 59 (1939).

7] M. Milbourn, The spectrographic analysis of soils and plant materials particularly for minor elements, J. Soc. Chem. Ind. Trans. 56, 205 (1937).

18] O. S. Duffendack and R. A. Wolfe, Analysis of caustic liquors for trace impurities, Ind. Eng. Chem. Anal. Ed. 10, 161 (1938).

[9] V. R. Ells, The Lundegardh flame method of spectrographic analysis, J. Opt. Soc. Am. 31, 534 (1941).

[10] C. C. Nitchie and G. W. Standen, An improved method of quantitative spectrographic analysis, Ind. Eng. Chem. Anal. Ed. 4, 182 (1932).

[11] E. Preuss, Quantitative spectral analysis in the carbon arc, Z. angew. Mineral. 1,167 (1938).

[12] H. I. Oshry, J. W. Ballard, and H. H. Schrenk, Spectrochemical determination of lead, cadmium, and zinc in dusts, fumes, and ores, J. Opt. Soc. Am. 31, 627 (1941).

[13] H. I. Oshry, J. W. Ballard, and H. H. Schrenk, Spectrochemical determination with mineral powders, J. Opt. Soc. Am. 32, 672 (1942).

[14] G. O. Freeman, Spectroscopic data concerning the presence of the less common elements in rocks, Am. Mineral. 2\%, 776 (1942).

[15] L. W. Strock, Blank and background effects on photographed spectral lines, J. Opt. Soc. Am. 32, 103 (1942).

[16] M. Slavin, Spectrochemical analysis of glass sand, Glass. Ind. 22, 341 (1941). 
[17] A. E. Austin and L. B. Bassett, Spectrochemical procedure in clay analysis, J. Am. Ceram. Soc. 26, 185 (1943).

[18] L. T. Steadman, Carbon arc in oxygen for the spectrochemical determination of potassium, Physiol. Revs. 63, 322 (1943).

[19] I. W. Wander, and W. R. Brode, The spectrochemical determination of potassium in leaf material, J. Opt. Soc. Am. 31, 402 (1941).

[20] W. C. Pierce, O. R. Torres, and W. W. Marshall, Quantitative spectrographic analysis in the arc with graphite electrodes, Ind. Eng. Chem. Anal. Ed. 12, 41 (1940).

[21] H. W. Dietert, Spectrographic analysis of briquetted tablets, J. Opt. Soc. Am. 31, 693 (1941).

[22] C. J. Neuhaus, $A$ study of the applicability of the pressed pellet electrode method to the spectrographic analysis of nickel alloys, J. Opt. Soc. Am. 33, 167 (1943).

[23] A. E. Ruehle and E. K. Jaycox, Some observations on the use of powders in spectrochemical analysis, J. Opt. Soc. Am. 33, 109 (1943).

[24] J. S. Owens, Analysis of organic materials for trace metallic impurities, Ind. Eng. Chem. Anal. Ed. 11, 646 (1939).

[25] B. F. Scribner and C. H. Corliss, An improved electrode holder for spectrographic analysis, NBS J. Research 30, 41 (1943) RP1515.

[26] F. G. Brockman and F. P. Hochgesang, Electrical ignition of the spectrographic arc, Ind. Eng. Chem. Anal. Ed. 14, 796 (1942).

[27] A. A. Berk and P. S. Roller, Direct determination of alkalis in portland cement, Concrete 43, 38 (1935).

[28] ASTM Standards C 114-42 Sections 20, 21.

Washington, June 17, 1944. 